\title{
IDEOLOGIA SEGUNDO JOHN THOMPSON: REFLEXÕES DA POLÍTICA DE EDUCAÇÃO NO PERÍODO DA DITADURA MILITAR BRASILEIRA. (1964-1985)
}

\author{
Adriana Lucinda de Oliveira ${ }^{1}$ \\ Luiz Everson da Silva ${ }^{2}$
}

\begin{abstract}
RESUMO
O presente trabalho apresenta uma reflexão sobre o conceito de Ideologia, segundo John Thompson, buscando identificar questões marcantes no período da ditadura militar brasileira (1964-1985). Nesse sentido, exemplificamos algumas estratégias ideológicas utilizadas pelo governo militar para manter uma relação de dominação após o golpe e destacamos a política educacional adotada na época.

Palavras-chave: Ideologia; Política de educação; Ditadura militar.
\end{abstract}

\section{IDEOLOGY BY JOHN THOMPSON: REFLECTIONS ON EDUCATION POLICY PERIOD OF BRAZILIAN MILITARY DICTATORSHIP. (1964-1985)}

\begin{abstract}
This paper presents a reflection on the concept of ideology according to John Thompson, seeking to identify outstanding issues during the Brazilian military dictatorship (19641985). In this sense exemplify some ideological strategies used by the military to maintain a relationship of domination after blow and highlight the educational policy adopted at the time.
\end{abstract}

Keywords: Ideology; Politics education; Military dictatorship.

O presente ensaio objetiva uma aproximação ao conceito ideologia, a partir da compreensão do termo, segundo John Thompson (2009), tendo como referência o contexto da ditadura militar no Brasil e seus reflexos na política educacional.

John Thompson é um estudioso inglês que defende que a cultura moderna encontra centralidade nos meios de comunicação, sendo esses vitais para o controle de poder na sociedade. Nessa perspectiva, toda e qualquer análise social tem que passar necessariamente pela análise da indústria midiática, expressa na relação entre ideologia e meios de comunicação. $O$ autor defende uma concepção crítica de ideologia, compreendendo-a como o uso de ideias, estratégias, formas simbólicas que, em determinados contextos, servem para estabelecer (produzir, criar, instituir e sustentar, manter e reproduzir) sistematicamente desigualdades sociais, entendidas como relações de poder ou de dominação. $\mathrm{O}$ autor destaca, no entanto, que as formas simbólicas não são ideológicas per si, mas dependem do contexto sócio-histórico em que são inseridas. Afirma que as: 
estratégias particulares de construção simbólica ou tipos particulares de formas simbólicas não são ideológicos em si mesmos: se o sentido gerado pelas estratégias simbólicas ou difundido pelas formas simbólicas serve para estabelecer ou sustentar relações de dominação, é uma questão que deve ser respondida somente pelo exame dos contextos específicos dentro dos quais as formas simbólicas são produzidas e recebidas, somente através do exame dos mecanismos específicos através dos quais elas são transmitidas dos produtores para os receptores, e somente através do exame de sentido que essas formas simbólicas possuem para os sujeitos que as produzem e as recebem. (THOMPSON, 2009, p. 89).

Essas relações de dominação estão permeadas de conflitos e assimetrias de classe, raça, gênero, orientação sexual, opção religiosa e idade. No entanto, "[...] o sujeito é ativo e mantém a capacidade de, em alguma medida, contrapor-se ao status quo". (NASCIMENTO, 2010, p.39).

Em sua análise, o referido autor apresenta 5 modos de operação da ideologia: legitimação, dissimulação, unificação, fragmentação e reificação e suas respectivas estratégias típicas de operação ideológica, conforme quadro abaixo.

\begin{tabular}{|c|c|}
\hline Legitimação & Racionalização \\
& Universalização \\
& Narrativização \\
\hline Dissimulação & Deslocamento \\
& Eufemização \\
& Tropo (sinédoque, metonímia, metáfora) \\
\hline Unificação & Padronização \\
& Simbolização da unidade \\
\hline Fragmentação & Diferenciação \\
& Expurgo do outro \\
& Estigmatização \\
\hline Reificação & Naturalização \\
& Eternalização \\
& Passifização \\
\hline
\end{tabular}

Quadro I - Modos de Operação da Ideologia. (THOMPSON, 2009, p. 81).

$\mathrm{O}$ autor destaca que esse quadro caracteriza-se em um meio metodológico, mas que não se pode identificar os modos como sendo os únicos pelos quais a ideologia opera: sua intenção é apenas exemplificar os tipicamente associados; evidencia, ainda, que nem sempre tais estratégias ou modos podem ser consideradas intrinsecamente ideológicos: só o serão se estiverem servindo para estabelecer relações de dominação. (ARAUJO, 2010, p. $34)$.

Nessa perspectiva, Thompson defende que uma análise deve estar amparada em um tripé: análise sócio-histórica, análise formal ou discursiva e a interpretação/re-intepretação. A análise sócio-histórica centra-se nas "condições sociais e históricas da produção, circulação e recepção das formas simbólicas" (THOMPSON, 2009, p. 34). Com isso, o contexto e suas influências sociais, políticas, econômicas, culturais e históricas são o fundamento da análise discursiva, com suas características estruturais, padrões e relações. 
(THOMPSON, 2009, p.369). A interpretação/reintepretação implica em um movimento de síntese, por uma construção criativa de possíveis significados. (THOMPSON, 2009, p. $375)$.

Diante dessa rápida exposição da proposta de Thompson, apresentamos um exercício de aplicação de sua metodologia, tendo como referência a política educacional no período do governo militar no Brasil. Objetivamos exemplificar algumas estratégias ideológicas utilizadas pelo governo militar para manter uma relação de dominação após o golpe e destacamos a política educacional adotada.

Para tanto, faz-se necessário um resgate sucinto sobre o contexto da ditadura militar para compreendermos seus reflexos na política educacional e a dimensão ideológica subjacente.

A diversa bibliografia aborda a temática do golpe militar de diferentes formas, enfatizando o contexto de instabilidade econômica, a crise do sistema político e da democracia populista e a crise institucional. Essas crises expressavam a dificuldade do sistema político de processar as demandas populares, compreendidas pelas forças políticas como caos, desordem, ameaça comunista, lidas pela classe média urbana como prenúncio da popularização da política. Assim,

O golpe de 1964 representou a aliança entre a burguesia industrial e financeira (nacional e internacional), o capital mercantil, latifundiários, intelectuais tecnocratas e militares. As crises política e econômica unidas ao "medo comunista" forneceram às Forças Armadas, respaldadas pela articulação dos estratos da classe dominante, as razões para intervir na crise hegemônica do Estado brasileiro implementado em 1946 nos moldes liberais, agora, ineficiente e incapaz de garantir as relações essenciais de dominação capitalista. A justificativa utilizada pelos militares com vistas a dar legalidade ao golpe foi orientada pelo discurso da necessidade de combate ao comunismo, a preservação dos princípios democráticos e a urgência de promover o desenvolvimento capitalista para a construção do Brasil enquanto Grande Potência Mundial. (SANTOS \& BEZERRA NETO, 2010, p. 117).

Podemos afirmar que os militares tinham uma agenda negativa, pois eram anticomunistas, antipopulistas, contra a corrupção, a subversão; se colocavam em defesa da ordem, da disciplina, da hierarquia e eram adeptos de um moralismo conservador e reformador. (CODATO, 2004).

As análises realizadas a posteriori, apontam para a existência de divergências internas, facções que disputavam o poder: os moderados, representados pelo General Castelo Branco, e a linha dura, encabeçada pelo General Médici.

Carlos Fico afirma que os militares estavam imbuídos de uma "utopia autoritária", que agregava essas instâncias burocrático-repressivas da ditadura militar. A utopia autoritária pode ser compreendida como cimento ideológico, organizada na doutrina de segurança nacional ${ }^{3}$. Traduzia-se na crença de que seria possível eliminar todas as formas de dissenso (comunismo, subversão, corrupção) que impediam o Brasil de avançar, de tornar-se um "país de futuro", o "Brasil Potência", uma democracia ocidental cristã. (FICO, 2004). Dessa forma, 
$\mathrm{O}$ anticomunismo consistia, provavelmente, no elemento ideológico mais renitente da visão militar do mundo desde 1935, e funcionou, na conjuntura, como um mínimo denominador comum a todas as correntes castrenses. O coronel Gustavo Moraes Rego Reis, castellista, liberal e moderado, enfatizou que, na ausência de um "projeto" e de uma "ideologia", a "Revolução" só "pensava em deter o comunismo [...]. Não tinha nada de [projeto] social nem de [projeto] econômico, era o anticomunismo". Essa ideologia funcionava como o elemento de coesão entre as facções radicais e moderadas. (CODATO, 2004, p. 29, Grifos e aspas do autor).

Uma das sustentações dessa ideologia era o Instituto de Estudos Políticos e Sociais (IPES), fundado em 1961, por um grupo de empresários do Rio de Janeiro e de São Paulo, articulados com empresários multinacionais e com a Escola Superior de Guerra, que "em suas ações ideológica, social e político-militar desenvolvia doutrinação por meio de guerra psicológica, fazendo uso dos meios de comunicação de massa visando desagregar em todos as organizações a defesa dos interesses populares". (SAVIANI, 2008, p. 294).

Em contrapartida, era objetivo também dos militares e empresários a retomada do desenvolvimento, suprimindo os avanços do nacionalismo-populista. Nesse sentido, as "promessas definidas ainda em 1964 foram a redução da inflação para 10\% a.a. e a retomada do crescimento a taxas ao redor de 6\% a.a.". (MACARINI, 2000, p. 2). Para tanto, a ditadura militar adotou uma estratégia de desenvolvimento fundada em três linhas de ação que se complementavam: a) reorientou o processo de concentração da riqueza e da renda; b) reduziu a taxa do salário real básico com respeito à produtividade média do sistema; e c) fomentou, em particular, mediante subsídios, a exportação de produtos industriais, objetivando aliviar os setores produtivos que enfrentavam insuficiência de demanda. (FERREIRA JR; BITTAR, 2008 p. 340). Assim, a composição do receituário adotado pelo modelo econômico tinha os seguintes ingredientes:

[...] arrocho salarial; concentração de riqueza; financiamento do capital por meio de subsídios, correção monetária como mecanismo de controle inflacionário; adoção de uma política governamental muito bem sucedida, que visava atrair as grandes empresas transnacionais e fomentar a expansão das subsidiárias destas já instaladas no País. (FURTADO, 1974, p. 103).

É nesse cenário que se delineia uma política de educação preocupada com a rentabilidade dos investimentos educacionais, concebendo educação como mercadoria. Essa visão repercute na sociedade em termos de crescimento econômico, e, nos indivíduos, quanto à melhoria de renda, através de uma maior qualificação para o mercado de trabalho. (SOBRAL, 2000).

Nessa perspectiva, tem-se uma educação direcionada para atender as demandas do mercado, uma concepção pedagógica autoritária e produtivista na relação entre educação e mundo do trabalho. "A educação no âmbito do regime militar foi concebida como instrumento a serviço da racionalidade tecnocrática, com o objetivo de viabilizar o slogan Brasil Grande Potência". (FERREIRA JR; BITTAR, 2008 p. 336):

A política educacional do período entre 1964 e 1985 estava, em última instância, vinculada organicamente ao modelo econômico que acelerou, 
de forma autoritária, o processo de modernização do capitalismo brasileiro. Ainda mais: foram reformas educacionais que estavam inseridas num contexto histórico de transição de uma sociedade agrária para uma sociedade urbano-industrial, cujas transformações societárias se desenrolavam desde 1930. (FERREIRA JUNIOR; BITTAR, 2008, p. 336).

Os meios de comunicação de massa foram de central importância no período, disseminando um conjunto articulado de idéias, valores, opiniões e crenças, segundo o qual a tecnocracia era a melhor forma de governar a sociedade brasileira. (FERREIRA JUNIOR; BITTAR, 2008).

No tocante à questão educacional, os tecnocratas defendiam como pressuposto básico a aplicação da "teoria do capital humano", como fundamentação teóricometodológica instrumental para o aumento da produtividade econômica da sociedade. A tecnocracia brasileira era filiada aos ditames emanados da "escola econômica" sediada na Universidade de Chicago (EUA) e, portanto, afeita às teorias aplicadas à educação desenvolvidas por Theodore W. Schultz (1902-1998). Assim,

A "instrução e a educação" eram, antes de tudo, valores sociais de caráter econômico. Portanto, a "instrução/educação" é considerada como um "bem de consumo", cuja principal propriedade é ser "um bem permanente de longa duração", por conseguinte, diferente de outras mercadorias consumidas pelos indivíduos durante as suas vidas. (FERREIRA JUNIOR; BITTAR, 2008, p. 343, grifos e aspas nossos).

Essa vinculação entre educação e mercado, entre processo formativo e produtivo, subordina a educação aos ditames e necessidades do capital. A educação acumula, ainda, a função de disciplinar a pobreza, de sustentar e justificar o status quo.

Segundo Saviani, ao debater a política educacional e as realizações da ditadura militar no Brasil, destaca três aspectos que se fazem presentes, ainda hoje, na educação brasileira: a vinculação da educação pública aos interesses e necessidades do mercado; o favorecimento da privatização do ensino; a institucionalização da pós-graduação. (SAVIANI, 2008, p. 295).

Essa conjuntura, suas implicações e reflexos foram objeto de estudos de vários pesquisadores (Dermeval Saviani, Gaudêncio Frigotto, Miguel Arroyo, entre outros), haja vista seus reflexos na atualidade. Nossa tentativa aqui, como já dissemos, é fazer uma aproximação dessa realidade, buscando identificar estratégias utilizadas para reproduzir e manter relações de dominação. Em plena ditadura militar, estava declarada a relação de dominação, contudo, diferenciadas foram as formas de manutenção, sustentação e legitimação adotadas.

Após a visualização do contexto da ditadura militar brasileira, retomamos a análise a partir da concepção de ideologia de Thompson, correlacionando os modos de operação da ideologia, possíveis estratégias de construção simbólica (vide quadro I) e as intencionalidades da educação, pautada na teoria do capital humano, adotadas no período militar, quais sejam:

Garantir a unidade nacional e legitimar o sistema, contribuir para a coesão e controle social, reproduzir a sociedade e manter a divisão 
nacional, promover a democracia da representação, contribuir para a mobilidade e ascensão social, apoiar o processo de acumulação, habilitar técnica, social e ideologicamente os diversos grupos de trabalhadores para servir ao mundo do trabalho, compor a força de trabalho, preparando, qualificando, formando e desenvolvendo competências para o trabalho, proporcionar uma força de trabalho capacitada e flexível para o crescimento econômico. (OLIVEIRA, 2009, p. 238).

Iniciamos nossa análise pela legitimação, modo de operação da ideologia, que se caracteriza por diferenciadas maneiras de validar as relações de dominação e apresentá-las como justas. Guareschi complementa ao afirmar:

O que fazemos tem de ser legitimado. E é nesse momento que facilmente escamoteamos a realidade, afirmando coisas, ou trazendo informações que mostram uma parte apenas, escondendo muitas outras. Há certas "verdades" legitimadoras que são consideradas, pela população em geral, como sendo absolutas e inegáveis. Uma delas é quando, por exemplo, se afirma que alguma coisa é resultado de "pesquisa científica". A ciência e o científico são apresentados como se fossem a última palavra. $\mathrm{Na}$ verdade, o que se quer, muitas vezes, é garantir proveito ou lucro particular (GUARESCHI, 2011, p.3, aspas do autor).

O exemplo da pesquisa científica que legitima verdades é evidenciado de maneira recorrente no ambiente educacional, considrando que o espaço escolar é concebido como centro do processo de formação, embasado teoricamente e cientificamente. Ou seja, não deve ser questionado. No período militar, as possibilidades de questionamentos eram vigiadas, cerceadas, sendo proibido o acesso a determinadas leituras tidas como ameaças ao sistema. Na educação, a produção de Paulo Freire e Karl Marx, por exemplo, eram consideradas comunistas, irreverentes, revolucionárias, ocultando concepções críticas e libertárias de educação. A ideologia como legitimação pode ser expressa em formas simbólicas através de uma variedade de estratégias; destacamos a racionalização e universalização.

Ao conceber que a educação deve contribuir para "garantir a unidade nacional e legitimar o sistema" (OLIVEIRA, 2009, p. 238), a estratégia da racionalização toma importância "através da qual o produtor de uma forma simbólica constrói uma cadeia de raciocínio que procura defender, ou justificar, um conjunto de relações ou instituições sociais, e com isso persuadir uma audiência de que isso é digno de apoio". (THOMPSON, 2009, p. 83). Nessa perspectiva justificou-se também o processo de privatização do ensino superior, tanto que, entre 1968 e 1976, o número de instituições públicas de ensino superior passou de 129 para 222, enquanto as instituições privadas saltaram de 243 para 663. (SAVIANI, 2008, p.300)

Da mesma forma, há a estratégia de universalização, em que os interesses de alguns são apresentados como de todos. Um exemplo disso foi a célebre expressão adotada pelos governantes e reproduzida por várias pessoas e instituições sociais (com destaque para a escola): "Todos devemos contribuir para o desenvolvimento do nosso país. Devemos deixar o bolo crescer para depois dividi-lo". A política educacional reforçava o compromisso de todos para o bem comum, universalizando os interesses dos grupos econômicos e militares: 
Como exemplo desse chamamento patriótico, podemos citar as propagandas repetidas constantemente na imprensa escrita e falada acerca da importância da "Revolução", que enalteciam o potencial industrial do Brasil e o dever que cada cidadão tinha em contribuir com esse progresso. Esse dever de contribuição dizia respeito aos desfiles em dias cívicos, ao compromisso de delação aos órgãos policiais de vizinhos, parentes e conhecidos que tivessem envolvimento com atividades "subversivas", ao cumprimento das determinações legais do Estado, sem questionamentos, ao respeito pelas autoridades etc. (ABREU; INÁCIO FILHO, 2006, p. 126 , aspas do autor).

Podemos citar, ainda, o decreto Lei 869/68, que instituiu a disciplina Moral e Cívica ${ }^{4}$, como obrigatória em todos os nívies de ensino ${ }^{5}$, com o objetivo de exaltar o nacionalismo e o civismo dos alunos e privilegiar o ensino de informações factuais em detrimento da reflexão e da análise. Nesse sentido,

A institucionalização da disciplina de Educação Moral e Cívica pelo Regime Militar procurou construir um ideário patriótico, com uma nação forte, que ressaltava os valores da moral, da família, da religião/fé e da defesa da Pátria e inculcava valores anticomunistas nos jovens e crianças. A EMC nos currículos explicitava como o Estado e os grupos dirigentes lidavam com a escolarização: a finalidade do ensino seria à formação genérica de um cidadão, amante da pátria e defensor de princípios moralizadores. Nesta proposta de nação coletiva, seriam eliminadas as possíveis diferenças, tensões e desigualdades, o único lugar possível era o do ser brasileiro, indivíduo coletivo. (FILGUEIRAS, 2013, p. 4).

A dimensão político-ideológica presente nessa perspectiva de educação remete a uma concepção positivista de educação, na qual o homem/mulher deve se adequar à sociedade em que vive, legitimando passivamente a hierarquia instituída:

Deste modo, o regime autoritário e as elites burguesas dominantes garantiriam a manutenção da ordem e do status quo. A educação passou a ser uma importante ferramenta de intervenção do projeto ideológico do Estado Autoritário. Tal projeto não ficará restrito só na implantação das disciplinas de EMC, OSBP e EPB. À criação dos Centros Cívicos Estudantis, o culto aos símbolos cívicos (Lei 5.700/71), a Educação Física e o Ensino Religioso também foram utilizadas para alcançar os objetivos propostos pelos técnicos do governo ditatorial. (VARGAS; SANTOS, 2012, p. 7).

Outro modus operanti de ideologia identificado é o da unificação, que se caracteriza pela construção de uma identidade coletiva de caráter unificador e que contemplaria todas as diferenças. Entre as estratégias de unificação, destacamos a padronização, que se refere à adoção de formas simbólicas para construir uma identidade coletiva. O próprio Thompson exemplifica a adoção de uma linguagem nacional, buscando unificar variações linguísticas em um país. Esse exemplo ganha concretude nas cidades de colonização germânicas do estado de Santa Catarina (como Blumenau, Indaial, Pomerode e Joinville), que, no período militar, foram proibidas de utilizarem a língua alemã no ambiente escolar. 
Na ideologia como unificação, destacamos, ainda, a estratégia de simbolização da unidade, que "envolve a construção de símbolos de unidade nacional como bandeiras, hinos nacionais". (THOMPSON, 2009, p. 86). No período militar, o hasteamento diário da bandeira com a entoação do hino nacional denotou a estratégia de construção simbólica da ideologia. A estratégia de simbolização da unidade expressa-se também na realização de campanhas publicitárias incentivando o amor à pátria, o culto à bandeira, o valor de ser brasileiro, a necessidade de todos se envolveram e se dedicarem para o desenvolvimento do país, sendo a campanha publicitária "Brasil: ame-o ou deixe-o"6 emblemática nesse sentido.

A ideologia como fragmentação também pode ser identificada através da segmentação de grupos ou indivíduos que podem representar um desafio aos grupos dominantes. A diferenciação e o expurgo do outro caracterizam-se em estratégias de diferenciação na medida em que as diferenças e divisões dos grupos são utilizadas para impedir o acesso ao poder ou para estigmatizar os sujeitos.

Os objetivos, assumidos pela política educacional no período militar, de "reproduzir a sociedade e manter a divisão nacional e de contribuir com a mobilidade e a ascensão social" apresentam consonância com as estratégias de construção simbólica de diferenciação. $\mathrm{O}$ acesso diferenciado à educação de qualidade expressa essa estratégia na medida em que tem limitado historicamente a população empobrecida de estabelecer uma outra lógica de organização do trabalho. Esse acesso constitui-se como uma das únicas possibilidades de ascensão social; porém, a baixa qualidade e a necessidade de ingresso prematuro no mundo do trabalho da maioria da população, evidenciam as diferenciadas condições de acesso às universidades de qualidade e a postos de trabalhos que exigem altos graus de qualificação.

O tratamento ridicularizante dos filhos/as das famílias alemães, que demonstravam dificuldade de pronunciar corretamente a letra $\mathrm{R}$, no ambiente escolar, apresenta-se também, como exemplo de expurgo do outro.

Destacamos, ainda, o modo de operação reificação, identificado por Thompson. A reificação refere-se à eliminação ou ofuscamento do caráter sócio-histórico dos fenômenos. "Processos são retratados como coisas, ou como acontecimentos de um tipo quase natural, de tal modo que seu caráter social e histórico é eclipsado". (THOMPSON, 2009, p. 87).

A teoria do capital humano, que fundamentou a política educacional no período militar, coisifica a educação ao concebê-la como mercadoria a ser consumida e não como direito social historicamente conquistado, principalmente, por negros, mulheres e pobres.

Entre as estratégias de construção simbólica de reificação destacamos a naturalização, que, como o termo já indica, naturaliza processos sociais, destituindo-os de seu caráter sócio-histórico. A naturalização é

[...] uma das principais armas de manutenção de situações de dominação e de acobertamento da realidade [...]. No momento, então, em que eu "naturalizo", isto é, considero como determinado, algo que é fruto da ação humana, torno-me escravo no que há de mais profundo em mim, que é minha consciência. Isto me impede e me impossibilita de lutar, sujeitando-me ao determinismo dessas criações que deixam de ser questionadas e se apresentam como "absolutas". (GUARESCHI, 2011, p.3, aspas do autor). 
Os objetivos de habilitar técnica, social e ideologicamente os diversos grupos de trabalhadores para servir ao mundo do trabalho, compor a força de trabalho, preparando, qualificando, formando e desenvolvendo competências e proporcionar uma força de trabalho capacitada e flexível para o crescimento econômico demonstram a estratégia de naturalização, pois ofuscam diferentes interesses de grupos, naturalizando que os filhos dos/as trabalhadores/as devem ser preparados para atender às necessidades do mercado. Esvazia-se o caráter sócio-histórico da divisão social do trabalho e sua relação com o acesso diferenciado à educação.

\section{Considerações finais}

Faz-se necessário reafirmar que, a partir da discussão proposta por Thompson, não podemos apontar de antemão a existência ou não de processos ideológicos, já que a ideologia para se efetivar vai depender dos sujeitos, de como estes recebem as diferenciadas formas simbólicas, as traduzem e dão sentido e significado. A tentativa aqui foi de apresentar uma reflexão evidenciando as diferenciadas possibilidades de manutenção de relações assimétricas de dominação no contexto educacional e a premência de uma vigilância constante para suprimir e superar as diferentes estratégias de reprodução, manutenção e aprofundamento dessas relações, pelos quais os processos educativos são transpassados. Vivemos hoje em uma democracia, contudo, a história nos aponta ainda hoje os resquícios da ditadura militar e a vigência de processos ideológicos que sustentam e legitimam a dominação.

A concepção de educação capitaneada e direcionada para o capital, para o mercado, permanece atual, em detrimento de uma educação para a crítica, para o pensamento, para a irreverência, para a ação política. Presenciamos um processo de formação esvaziado, reduzido, mercantilizado, que anula ou diminui significativamente a possibilidade da crítica ao status quo e que está estruturado para suprir as necessidades do sistema produtivo, para resolver problemas do mundo do trabalho, o que parece coadunar-se, enfaticamente, com a lógica de adaptação ao sistema existente. Acreditamos que a educação seja uma das portas para romper com esse ciclo vicioso, na medida em que pode nos trazer a possibilidade da crítica, do questionamento, da criatividade, da criação, da produção, com autonomia, de conhecimento.

Ao compreender a formação como totalidade concreta, admite-se que sua constituição se dá no conjunto das relações sociais do mundo presente. Na atualidade, tais relações assentam-se e desenvolvem-se inseridas no modo de produção capitalista, que, ao longo do tempo, tem estabelecido estratégias e ações para reprodução e ampliação do capital. As classes dominantes, através do Estado, têm utilizado histórica e sistematicamente a educação formal para alcançar seus objetivos, fragmentando conhecimentos, relações, sistemas e insistido na proposta individual e meritocrática. Portanto, a formação como totalidade concreta aqui assumida, dar-se-á no tensionamento com a proposta instituída pelo capitalismo.

\section{Referências}

ABREU, Vanessa Kern de; INÁCIO FILHO, Geraldo. Educação moral e cívica - doutrina, disciplina e prática educativa. In: Revista HISTEDBR On-line, Campinas, n.24, p. 125 -134, dez. 2006. 
ARAÚJO, Débora Cristina de. Relações raciais, discurso e literatura infanto-juvenil. Dissertação (Mestrado em Educação). Curitiba: Universidade Federal do Paraná, 2010.

FERREIRA JUNIOR, Amarilio; BITTAR, Marisa. Educação e ideologia tecnocrática na ditadura militar. In: Cad. Cedes, Campinas, vol. 28, n. 76, p. 333-355, set./dez. 2008.

FILGUEIRAS, Juliana Miranda. O livro didático de educação moral e cívica na ditadura de 1964: a construção de uma disciplina. Disponível em: http://www.faced.ufu.br/colubhe06/anais/arquivos/302JulianaMirandaFilgueiras. Acessado em: 08/02/2011.

GUARESCHI, Pedrinho. Ideologia: um terreno minado. Disponível em: http://serpensar.vilabol.uol.com.br/ideologia.htm. Acessado em: 08/02/2011. [parte do livro: Psicologia social crítica: como prática de libertação. Porto Alegre: EDIPUCRS, 2004. 138p. P.7481].

NASCIMENTO, Sergio Luis do. Relações raciais em livros didáticos de ensino religioso do ensino fundamental. Dissertação (Mestrado em Educação). Curitiba: Universidade Federal do Paraná, 2009.

OLIVEIRA, João Ferreira de. A função social da educação e da escola pública: tensões, desafios e perspectivas. In: FERREIRA, Eliza Bartolozzi; OLIVEIRA, Dalila Andrade. Crise da escola e políticas educativas (Orgs.). Belo Horizonte: Autêntica editora, 2009, p. 237-252.

SAVIANI, Dermeval. O legado educacional do regime militar. In: Cad. Cedes, Campinas, vol. 28, n. 76, p. 291-312, set./dez. 2008

THOMPSON, John B. Ideologia e cultura moderna: teoria social crítica na era dos meios de comunicação de massa. Tradução de Carmem Griscietalli. Rio de Janeiro: Vozes, 2009.

Notas

1 Professora Assistente do curso de Serviço Social da Universidade Federal do Paraná (UFPR) e doutoranda do Programa de Pós-Graduação em Políticas Públicas da UFPR.

2 Professor Adjunto do curso de Licenciatura em Ciências da Universidade Federal do Paraná (UFPR) e Doutor em Química pela Universidade Federal de Santa Catarina.

3 A doutrina de segurança nacional compreende um conjunto de princípios políticos, geopolíticos e estratégicos de psicologia social que orientavam a formação dos militares no período de 1950 a 1970.

4 A escola era o centro das atividades cívicas, dela o civismo deveria irradiar para toda a comunidade; assim planejava o Estado. No entanto, não deixava essa missão somente para a escola, mobilizando também a imprensa e órgãos de movimentos sociais, como associações de bairros e sindicatos, esses dois últimos por ação mais violenta do que coercitiva (ABREU; INÁCIO FILHO, 2006, p, 133).

5 O conteúdo do civismo e patriotismo foi denominado nos diferentes níveis educacionais da seguinte forma: EMC - Educação Moral e Cívica ( $1^{\mathrm{a}}$ a $6^{\mathrm{a}}$ série do $1^{\mathrm{o}}$ grau), OSPB - Organização Social e Política do Brasil $\left(7^{\mathrm{a}}\right.$ e $8^{\mathrm{a}}$ série do $1^{\mathrm{o}}$ grau, ensino médio) e EPB - Estudos dos Problemas Brasileiros (ensino superior).

6 Com o bordão "Brasil, Ame ou deixe-o", o presidente General Médici ordenou a total censura a livros, filmes, músicas e quaisquer outros tipos de manifestações contra o regime, amparado no Ato Institucional ${ }^{\circ}$ 5 O Brasil vivia o período de milagre econômico e o período de maior censura, opressão e tortura.

Recebido em fevereiro-13

Aprovado em julho-13 